\title{
IMPLEMENTASI WIRELESS MONITORING ENERGI LISTRIK BERBASIS WEB DATABASE
}

\author{
Irwan Dinata, Wahri Sunanda \\ Jurusan Teknik Elektro, Fakultas Teknik \\ Universitas Bangka Belitung \\ e-mail: irwandinata@ubb.ac.id
}

\begin{abstract}
Abstrak - Implementasi Wireless Monitoring Energi Listrik Berbasis Web Database ini dirancang untuk menggantikan sistem pengukuran energi listrik secara manual dan konvensional. Perangkat ini terdiri 4 (empat) bagian yaitu sensor, processor, display dan network. Bagian sensor terdiri dari Current Transformer dan AC to AC Power Adapter. Processor digunakan Arduino UNO yang akan mengolah hasil sensor, display menggunakan Liquid Crystal Display (LCD) tipe untuk menampilkan data keluaran real time. Dan bagian terakhir yaitu network terdiri dari Ethernet Shield, 3G Router, 3G Modem untuk komunikasi ke Database Server sebagai tempat penyimpanan tetap dan pengolahan data lebih lanjut. Pada pengujian dengan total beban nominal 120 watt menunjukkan bahwa nilai Vrms yang tampil di LCD Wireless Energy Monitoring sebesar 218 volt, nilai Vrms hasil pengukuran Clamp Meter sebesar 216 volt. Untuk nilai Irms di LCD Wireless Energy Monitoritng 0,44 ampere, nilai Irms hasil pengukuran Clamp Meter 0,5 ampere. Nilai daya nyata di LCD Wireless Energy Monitoring 92 watt, nilai daya nyata hasil pengukuran Clamp Meter 84 watt. Sedangkan faktor daya di LCD Wireless Energy Monitoring 0,97 dan faktor daya hasil pengukuran Clamp Meter 0,99.
\end{abstract}

Kata kunci: wireless monitoring, real power, power factor.

\begin{abstract}
Web Database based wireless device for monitoring electricity consumption is designed to substitute manual and conventional measurement system. This device consists of sensor, processor, display and network. The sensor consists of current transformer and AC to AC Power Adapter. The processor is Arduino UNO which process sensor output. Liquid crystal device (LCD) is used to display real time output. The last part of the device is network composed of Ethernet Shield, 3G Modem for communication with Database Server as data further processing and storage. The testing with nominal total load 120 watt shows that Vrms value on LCD of the device is 218 volt, Vrms value measured with clamp meter is 216 volt. Irms value on LCD of the device is 0,44 ampere, Irms value measured with clamp meter 0,5 ampere. The real power value on LCD of the device is 92 watt, the real power value measured with clamp meter is 84 watt. The power factor value on LCD of the device is 0,97 , the power factor value measured with clamp meter is 0,99 .
\end{abstract}

Keywords: wireless monitoring, real power, power factor.

\section{PENDAHULUAN}

Pertumbuhan energi listrik terus meningkat dari waktu ke waktu sejalan dengan meningkatnya kegiatan ekonomi dan kesejahteraan masyarakat. Peningkatan pertumbuhan energi listrik tersebut tentunya akan menghabiskan sumber energi tak terbaharukan yang ada sekarang jika pemanfaatannya tidak efektif dan efisien. Dalam pemanfaatan energi listrik tersebut terkadang tidak diketahui berapa banyak energi yang telah terpakai sehingga cenderung terjadi pemborosan energi lisrik. Oleh karena itu, untuk mengetahui besarnya energi listrik yang sedang terpakai, perlu dilakukan pengukuran penggunaan energi listrik tersebut. Pengukuran penggunaan energi listrik ini merupakan proses sebuah manajemen energi listrik yang sangat penting sehingga dengan mudah proses penghematan dan efisiensi bisa diperoleh.

Implementasi Wireless Monitoring Energi Listrik Berbasis Web Database ini dirancang untuk mendapatkan informasi-informasi yang berhubungan dengan pengukuran energi listrik antara lain Real Power (Watt), Apparent Power (VA), Power Factor (\%), Voltage RMS (V), dan Current RMS (A) secara real time yang dapat 
diakses dari Jaringan Internet kapan saja. Pengukuran seperti diatas biasanya dilakukan dengan menggunakan alat ukur sederhana dan pencatatan masih manual sehingga data yang didapat tidak bisa dilakukan setiap saat dan hasilnya terlalu lama untuk didapatkan. Sistem ini terdiri dari perangkat keras dan perangkat lunak yang saling terhubung sehingga informasi yang disajikan dapat langsung diakses pada saat itu juga. Perangkat keras tidak dapat bekerja dengan efektif jika perangkat lunak tidak dirancang dengan benar. Perangkat ini dirancang untuk menggantikan sistem pengukuran energi listrik secara manual dan konvensional.

Perangkat ini terdiri 4 (empat) bagian yaitu sensor, processor, display dan network. Bagian sensor terdiri dari Current Transformer dan AC to AC Power Adapter. Processor digunakan Arduino UNO yang akan mengolah hasil sensor, display menggunakan Liquid Crystal Display (LCD) tipe untuk menampilkan data keluaran real time. Bagian terakhir yaitu network terdiri dari Ethernet Shield, 3G Router, 3G Modem untuk komunikasi ke Database Server sebagai tempat penyimpanan tetap dan pengolahan data lebih lanjut. Melalui perangkat ini kita dapat memantau penggunaan energi listrik setiap saat tanpa harus mendatangi lokasi titik pengukuran tersebut.

\section{TINJAUAN PUSTAKA}

\section{A. Arus Listrik}

Arus listik adalah mengalirnya elektron secara kontinyu pada konduktor akibat perbedaan jumlah elektron pada beberapa lokasi yang jumlah elektronnya tidak sama. Satuan arus listrik adalah Ampere. Satu ampere arus adalah mengalirnya elektron sebanyak $628 \times 10^{16}$ atau sama dengan satu coulumb per detik meliwati suatu penampang konduktor.

$$
i=\frac{q}{t} \quad \text { ampere] }
$$

Dimana:

$Q=$ Banyaknya muatan listrik dalam satuan coulomb

$i=$ Kuat Arus dalam satuan Amper.

$t=$ Waktu dalam satuan detik.

\section{B. Tegangan Listrik}

Tegangan atau seringkali orang menyebut dengan beda potensial (voltage) adalah kerja yang dilakukan untuk menggerakkan satu muatan (sebesar satu coulomb) pada elemen atau komponen dari satu terminal atau kutub ke terminal atau kutub lainnya, atau pada kedua terminal atau kutub akan mempunyai beda potensial jika kita menggerakkan atau memindahkan muatan sebesar satu coulomb dari satu terminal ke terminal lainnya. Keterkaitan antara kerja yang dilakukan sebenarnya adalah energi yang dikeluarkan, sehingga pengertian diatas dapat disederhanakan bahwa tegangan adalah energi per satuan muatan.

Secara matematis:

$$
v=\frac{d w}{d q} \quad[\text { volt }]
$$

\section{Daya Listrik}

Daya pada arus bolak-balik atau alternating current (ac) ada 3 macam yaitu daya aktif, daya reaktif dan daya nyata.

\section{Daya aktif}

Daya aktif digunakan secara umum oleh konsumen. Daya aktif inilah yang biasanya dapat dikonversikan dalam bentuk kerja. Satuan daya aktif dinyatakan dalam watt. Daya aktif (real power), didapat dari persamaan:

$$
P=V . I \cdot \cos \theta[k W]
$$

\section{Daya reaktif}

Daya reaktif adalah jumlah daya yang diperlukan untuk pembentukan medan magnet. Dari pembentukan medan magnet. Maka akan terbentuk fluks magnet. Satuan daya reaktif dinyatakan dalam VAr. Daya reaktif (reactive power), didapat dari persamaan:

$$
Q=V \cdot I \cdot \sin \theta\left[k V A_{r}\right]
$$

\section{Daya nyata}

Daya nyata adalah penjumlahan geometris dari daya aktif dan daya reaktif. Daya nyata merupakan daya yang diproduksi oleh perusahaan sumber listrik untuk diditribusikan ke konsumen. Satuan daya nyata ini dinyatakan dalam VA. Daya nyata (apparent power), didapat dari persamaan: 


$$
S=V . I[k V A]
$$

Daya aktif dan reaktif didefinisikan secara matematika sebagai berikut:

$$
P+J Q=\text { Vsrms.Irms }=S
$$

\section{Faktor Daya}

Faktor Daya bukan merupakan ukuran langsung dari efisiensi output-to-input, tetapi factor daya merupakan ukuran sebenarnya dari bagaimana kapasitas sistem tenaga listrik digunakan. Faktor daya atau power factor (pf) didefinisikan sebagai perbandingan antara daya aktif (real power) dalam $\mathrm{kW}$ dengan daya nyata (apparent power) dalam kVA. Persamaannya adalah:

$$
\begin{aligned}
\text { Faktor Daya }(\mathrm{pf}) & =k W+k V A \\
& =(V \cdot I \cdot \cos \theta) / V \cdot I \\
& =\cos \theta
\end{aligned}
$$

\section{E. Arduino}

Arduino adalah sebuah mikrokontroler single-board yang bersifat open-source seperti pada Gambar 1. Hardware mikrokontroler Arduino diprogram dengan menggunakan bahasa pemrograman wiring-based yang berbasiskan syntax dan library. Pemrograman wiring-based ini tidak berbeda dengan $\mathrm{C} / \mathrm{C}++$, tetapi dengan beberapa penyederhanaan dan modifikasi. Untuk memudahkan dalam pengembangan aplikasinya, mikrokontroler Arduino juga menggunakan Integerated Development Environment (IDE) berbasis processing. Mikrokontroler Arduino dapat dipasangkan dengan bermacam-macam sensor dan aktuator lainnya. Adapun sensor dan aktuator yang dapat dipasangkan pada Arduino seperti sensor gerak, ultrasonik, panas, suara, Ethernet Shield, LED Display dan yang lainnya.

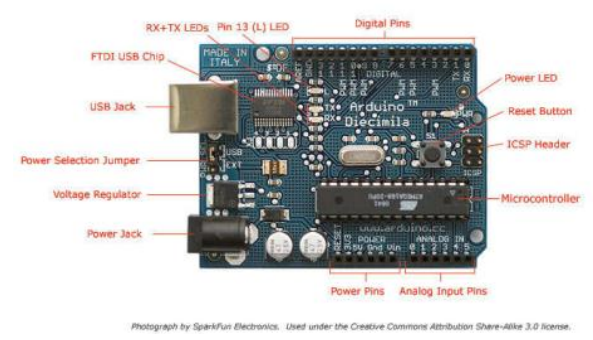

Gambar 1. Mikrokontroler Arduino UNO

\section{F. Sensor Tegangan}

Sensor tegangan digunakan untuk mengambil data besaran tegangan terhadap ujung terminal yang terhubung dengan beban. Pada aplikasinya sensor tegangan berupa suatu alat yang dikenal dengan AC to AC Power Adapter merupakan penurun tegangan rendah dari tegangan $\mathrm{AC}$ yang biasanya kita kenal di 220 Volt. Untuk menghindari bekerja langsung pada tegangan tinggi yang bisa membahayakan, sehingga $A C$ to AC Power Adapter akan membantu menurunkan tegangan menjadi sebesar 9-12 AC Volt. Keberadaan AC to AC Power Adapter sangat jarang terdapat dipasaran dikarenakan lebih cendrung $A C$ to $D C$ Adapter, hal tersebut dikarenakan hampir semua peralatan elektronik berdaya rendah menggunakan tegangan DC sebagai sumbernya. Sehingga untuk membuat $A C$ to AC Power Adapter lebih mudah dibuat dari trafo biasa yang sering kita gunakan ketika membuat DC Power Supply.

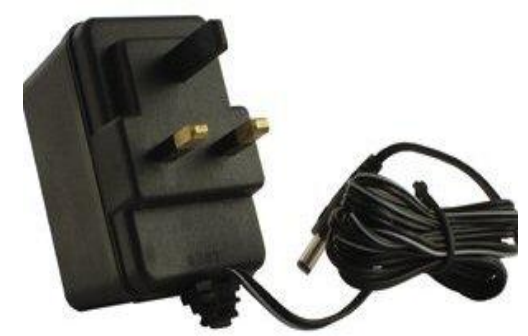

Gambar 2. AC to AC Power Adapter

\section{G. Sensor Arus}

Teknologi sensor arus hampir sama dengan teknologi sensor tegangan yaitu dengan menggunakan trafo arus yang dikenal dengan Current Trafo (CT) dan dengan menggunakan teknologi efek hall. Sensor ini tergolong komponen yang memiliki tingkat stabilitas yang baik. Jenis sensor arus yang banyak dipakai adalah The Yhdc current transformer dikenal sebagai CT sensor merupakan inti dari sebuah pengukuran arus listrik bolak balik, sebuah noninvansive sensor yang dapat mendeteksi aliran arus yang melalui sebuah kawat penghantar.

Dalam proses induksi, arus listrik yang melalui kawat sisi primer akan menghasilkan sebuah medan magnet pada inti ferrite CT sensor. Kawat pada sisi sekunder yang mengelilingi inti tersebut menghasilkan arus listrik kecil yang proporsional. Selanjutnya CT 
sensor dengan penambahan sebuah resistor kecil (Burden Resistor) akan menghasilkan keluaran berupa tegangan yang dapat diukur oleh Arduino.

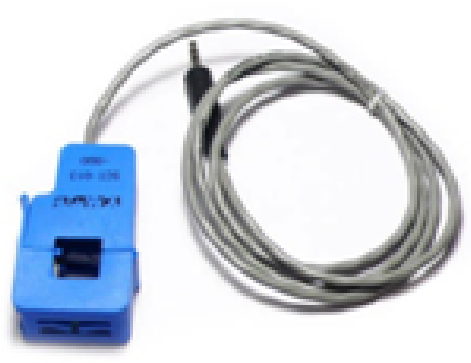

Gambar 3. The Yhdc Current Transformer

\section{H. Ethernet Shield}

Ethernet Shield merupakan perangkat tambahan yang digunakan untuk menghubungkan Arduino ke dalam jaringan komputer atau internet. Shield ini memakai WIZnet W5100 Ethernet Chip yang dapat memberi kemudahan untuk membuat arduino dapat diakses secara online. Penggunaan Shield ini disertai library Arduino untuk menulis sketch. Chip WIZnet W5100 Mendukung hingga empat koneksi soket secara simultan. Dalam menggunakan perangkat ini cukup dengan menancapkan Shield di atas Arduino Uno yang ada. Begitupun untuk pemrogramannya cukup menghubungkan Arduino dengan komputer via USB sebagaimana memprogram Arduino seperti biasa, serta menghubungkan Ethernet Shield dengan komputer atau hub atau router, dapat menggunakan kabel UTP Cat5 dengan konektor RJ45.

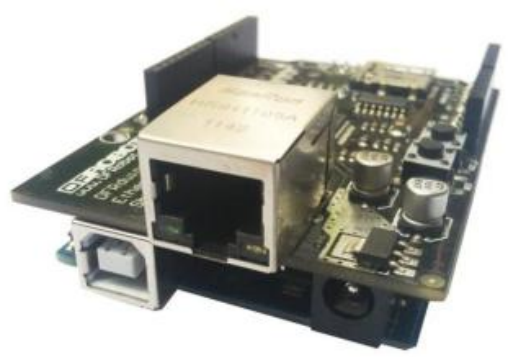

Gambar 4. Ethernet Shield

\section{Liquid Crystal Display (LCD)}

Kegunaan LCD banyak sekali dalam perancangan suatu sistem dengan menggunakan menggunakan mikrokontroler, LCD dapat berfungsi untuk menampilkan suatu nilai hasil sensor, menampilkan teks, atau menampilkan menu pada aplikasi mikrokontroler. Modul LCD matrix tersedia dengan konfigurasi 16 karakter dan 2 baris dengan setiap karakternya dibentuk oleh baris pixel. Adapun fitur yang disajikan dalam LCD ini adalah:

1. Terdiri dari 16 karakter dan 2 baris.

2. Mempunyai 192 karakter tersimpan.

3. Terdapat karakter generator terprogram.

4. Dapat dialamati dengan mode 4-bit dan 8bit.

5. Dilengkapi dengan back light

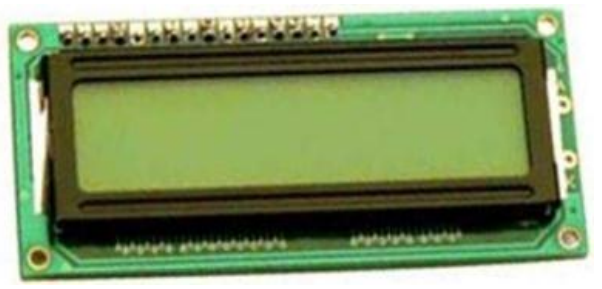

Gambar 5. LCD 2x16

\section{METODOLOGI}

Secara umum Implementasi Wireless Monitoring Energi Listrik Berbasis Web Database ini dimulai dengan mengambil keluaran dari sensor tegangan dan sensor arus untuk kemudian diolah oleh Arduino dan ditampilkan sebagai keluaran berupa Real Power (Watt), Apparent Power (VA), Power Factor (\%), Voltage RMS (V), dan Current RMS (A). Arsitektur sistem yang akan dibuat pada penelitian ini secara keseluruhan dapat dilihat pada gambar 5 dibawah ini.

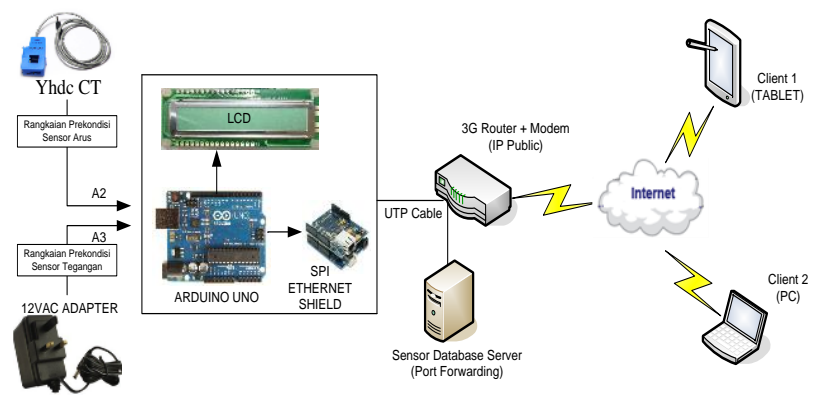

Gambar 6. Arsitektur Sistem

Sensor Arus YhDC CT dan sensor Tegangan 12 VAC Adapter akan membaca kondisi arus dan tegangan pada titik pengamatan. Nilai yang dikeluarkan sensor belum bisa dibaca dengan 
baik oleh Arduino UNO untuk itu diperlukan sebuah rangkaian prekondisi yang bisa membatasi tegangan keluaran sensor tersebut sekitar 1 Volt, sehingga tidak akan merusak Pin Analog Arduino (A2 dan A3). Selanjutnya Arduino UNO akan mengolah dan melakukan perhitungan nilai pembacaan tersebut untuk ditampilkan di LCD dan dikirimkan ke Sensor Database Server secara berkala. Data yang telah tersimpan di Database akan mudah dipanggil untuk ditampilkan dalam sebuah website aplikasi. Tentunya website ini dapat diakses via LAN maupun Internet.

\section{HASIL DAN PEMBAHASAN}

Pada pengujian ini bertujuan untuk melihat hasil tampilan aplikasi Website Energy Monitoring dari data hasil pengukuran yang telah tersimpan di-database. Data pengukuranakan dipanggil kembali dan ditampilkan dalam bentuk grafik serta proses otentikasi user sebagai pemilihan atas hak user dalam mengakses website tesebut.

\section{A. Grafik Pengukuran Real Time}

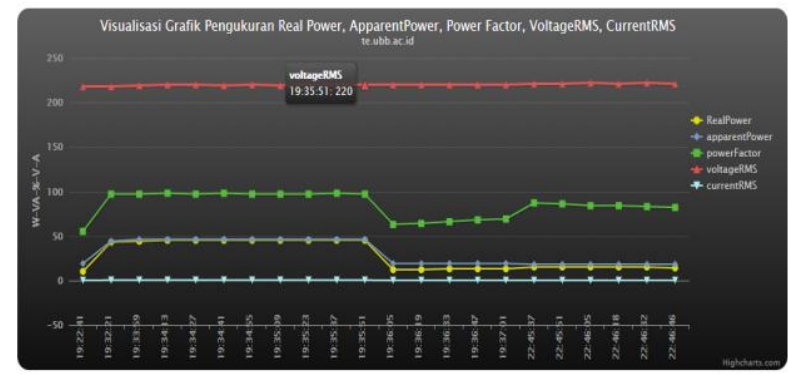

Gambar 7. Tampilan Grafik Pengukuran Real Time

Dari gambar diatas, ditampilkan sekaligus dalam bentuk visualisasi grafik semua data pengukuran yang tersimpan di database. Pada sumbu $\mathrm{x}$, merupakan tanggal dan waktu pengambilan data, sedangkan pada sumbu $\mathrm{y}$, satuan dari masing-masing besaran listrik yang telah diukur. Nilai tersebut akan berubah setiap saat dengan data sebanyak 40 plot per frame, dapat diketahui pemakaian listrik saat itu. Data yang telah ditampilkan tetap disimpan di database sehingga dapat diambil dan ditampilkan kembali.

\section{B. Manajemen Laporan Pengukuran}

Manajemen Laporan Pengukuran digunakan untuk membuat laporan hasil penggukuran berdasarkan masing-masing registrasi pengukuran. Gambar 8 memperlihatkan record data pada sebuah field database, yang berisi informasi pengukuran seperti time, date, realPower, apparentPower, powerFactor, voltageRMS, currentRMS. Pada tanggal 20-23 Agustus 2014, jam 19:22:41 s.d. 19:35:09 di tempat "Pengukuran A" pada seperti yang terlihat pada gambar 9, detail pengukuran Reg ID P001 yang berisi informasi pengambilan sampel data pengukuran dalam tampilan web. Dari data tersebut juga diperlihatkan nilai minimal, maksimal dan rata-rata.

\begin{tabular}{|c|c|c|c|c|c|c|c|c|c|}
\hline$\leftarrow T \rightarrow$ & & id & date & time & realPower & apparentPower & powerfactor & voltage RMS & currentRMS \\
\hline$\square 8$ & & 1 & 27.06 .2014 & 23:30:24 & 99 & 149 & 66 & 235 & 0.63 \\
\hline$\square 8$ & $x$ & 2 & 27.06 .2014 & 23:30:38 & 92 & 140 & 66 & 235 & 0.59 \\
\hline$\square \ell$ & $x$ & 3 & 27.06 .2014 & 23:30:52 & 97 & 146 & 66 & 235 & 0.62 \\
\hline$\square>$ & $x$ & 4 & 27.06 .2014 & 23:31:06 & 99 & 149 & 66 & 235 & 0.63 \\
\hline$\square 8$ & $x$ & 5 & 27.06 .2014 & 23:31:20 & 90 & 138 & 65 & 235 & 0.59 \\
\hline$\square \rho$ & $x$ & 6 & 27062014 & 23:31:34 & 93 & 142 & 65 & 235 & 0.60 \\
\hline$\square \rho$ & $x$ & 7 & 27.062014 & 23:31:48 & 91 & 139 & 66 & 235 & 0.59 \\
\hline 08 & $x$ & 8 & 27.06 .2014 & 23:32:02 & 90 & 137 & 65 & 235 & 0.58 \\
\hline$\square 8$ & $x$ & 9 & 27.06 .2014 & 23:32:16 & 89 & 137 & 65 & 235 & 0.58 \\
\hline$\square>$ & $x$ & 10 & 27.06 .2014 & 23:32:29 & 89 & 137 & 65 & 235 & 0.58 \\
\hline$\square \rho$ & $x$ & 11 & 27.06.2014 & $23: 32: 43$ & 89 & 136 & 65 & 235 & 0.58 \\
\hline 0 & $x$ & 12 & 27.06 .2014 & 23:32:57 & 92 & 140 & 66 & 235 & 0.60 \\
\hline$\square>$ & $x$ & 13 & 27.06 .2014 & 23.33:11 & 69 & 136 & 65 & 235 & 0.56 \\
\hline 0 & $x$ & 14 & 27.06.2014 & 23.33 .25 & 86 & 137 & 64 & 235 & 0.56 \\
\hline$\square>$ & $x$ & 15 & 27.06 .2014 & 23.33:39 & 94 & 143 & 65 & 235 & 0.61 \\
\hline 08 & $x$ & 16 & 27.06 .2014 & $23.33: 53$ & 89 & 137 & 65 & 235 & 0.58 \\
\hline 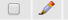 & $x$ & 17 & 27.06.2014 & 23:34:07 & 90 & 139 & 65 & 235 & 0.59 \\
\hline$\square 8$ & $x$ & 18 & 27.06 .2014 & 23:34:21 & 88 & 137 & 64 & 235 & 0.58 \\
\hline$\square \rho$ & $x$ & 19 & 27.06.2014 & 23:34:35 & 90 & 139 & 65 & 235 & 0.59 \\
\hline & $x$ & 20 & 27.06 .2014 & $23: 34: 49$ & 91 & 140 & 65 & 234 & 0.60 \\
\hline
\end{tabular}

\section{Gambar 8. Record Data Field Database}

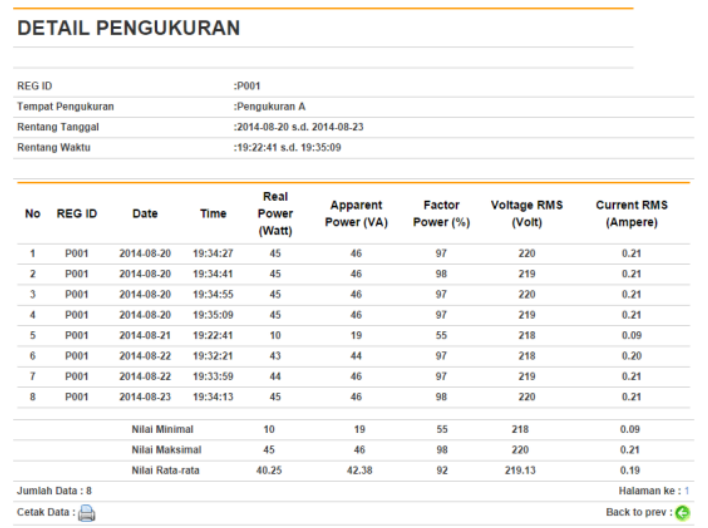

Gambar 9. Tampilan Detail Pengukuran Reg ID P001

\section{KESIMPULAN}

Dari hasil dan pembahasan yang telah dilakukan maka didapat beberapa kesimpulan sebagai berikut: 
1. Pada pengujian dengan total beban nominal 120 watt menunjukkan bahwa nilai Vrms yang tampil di LCD Wireless Energy Monitoring sebesar 218 volt, nilai Vrms hasil pengukuran Clamp Meter sebesar 216 volt. Untuk nilai Irms di LCD Wireless Energy Monitoritng 0,44 ampere, nilai Irms hasil pengukuran Clamp Meter 0,5 ampere. Nilai daya nyata di LCD Wireless Energy Monitoring 92 watt, nilai daya nyata hasil pengukuran Clamp Meter 84 watt. Sedangkan faktor daya di LCD Wireless Energy Monitoring 0,97 dan faktor daya hasil pengukuran Clamp Meter 0,99.

2. Pada website aplikasi Wireless Energy Monitoring yang telah dirancang, berhasil mengirimkan hasil pengukuran setiap saat ke Database Server.

\section{DAFTAR PUSTAKA}

[1]Sunanda, Wahri dan Irwan Dinata. "Penerapan Perangkat Wireless Monitoring Energi Listrik Berbasis Arduino dan Internet". Jurnal Amplifier, ISSN: 20892020, Volume 04 Nomor 02, November 2014: 21-23.

[2] Arduino Playground, http://www.arduino.cc [diakses pada 20 Oktober 2013].

[3]Open Enegy Monitor Project, http://openenergymonitor.org [diakses pada 20 Oktober 2013].

[4] Premeaux, Emery dan Brian Evans. "Arduino Project to Save The World". Springer Science and Business Media. New York. Chapter 7. Staying Current. 2011.

\section{Biodata Penulis}

Irwan Dinata, S.T., M.T., Menamatkan pendidikan S1 di Jurusan Teknik Telekomunikasi STT Telkom Bandung tahun 2008 dan S2 Wireless Communication Institut Teknologi Telkom Bandung tahun 2010. Mulai tahun 2010 bekerja sebagai Dosen di Jurusan Teknik Elektro Fakultas Teknik Universitas Bangka Belitung.

Wahri Sunanda, S.T., M.Eng., Menamatkan pendidikan S1 di Jurusan Teknik Elektro
Universitas Gadjah Mada tahun 2008 dan S2 pada tempat yang sama tahun 2010. Mulai tahun 2010 bekerja sebagai Dosen di Jurusan Teknik Elektro Fakultas Teknik Universitas Bangka Belitung. 